\title{
GAMBARAN PENGARUH PERINGATAN PERINGATAN KESEHATAN BERGAMBAR PADA KEMASAN ROKOK TERHADAP PERILAKU MEROKOK REMAJA DI SMKN 1 KOTA GIANYAR TAHUN 2019
}

\author{
Ni Luh Putu Devhy'), Anak Agung Oka Widana 2) \\ ${ }^{1,2}$ Rekam Medis Dan Informasi Kesehatan, STIKes Wira Medika Bali, Jl. Kecak no. \\ 9a, Denpasar, 80224 \\ Email: Deevhy@gmail.com
}

\begin{abstract}
Background: Smoking is a habit of a person's life behavior that can interfere with health for himself or for those around him. The prevalence of smoking in Indonesia is very high in various levels of society, especially in men ranging from children, adolescents and adults. The tendency of smoking continues to increase from year to year in both men and women, this of course is very worrying for all of us.

Objective: This study aims to assess the prevalence of smoking in adolescents of one of SMAKN 1 in the City of Gianyar, Assess the understanding, adolescents about the dangers of smoking in accordance with the Pictorial Health Warning (PKB) in a high school in the City of Gianyar, Assess the effect of $P K B$, the dangers of smoking on behavior smoking in teenagers in the City of Gianyar. Research Methods: This is an observational study with a cross-sectional design. The sample in this study was teenage boys at SMKN 1 Gianyar, during August 2019. Samples were randomly selected. Data collection through structured interviews using questionnaires that have been tested before, then analyzed descriptively.

Results: The average respondent was 15.9 years old, $100 \%$ were men, had a high school education, $97 \%-99 \%$ of respondents already knew the dangers of smoking, $74 \%$ of respondents tried smoking and the average age of trying cigarettes for the first time 14.2 years, then $68 \%$ after the PKB felt afraid to smoke and $30 \%$ who still wanted to smoke.

Conclusion: Most of SMAKN 1 teenagers in the City of Gianyar have a desire to stop smoking, therefore it is important to be followed up to improve the PKB so that they can help them in realizing the desire to stop smoking.
\end{abstract}

Keywords: Pictorial health warning, smoking behavior, the effect of warning.

\begin{abstract}
Abstrak
Latar Belakang: Merokok merupakan kebiasaan perilaku hidup seseorang yang dapat mengganggu kesehatan untuk diri nya sendiri maupun untuk orang disekitarnya. Prevalensi merokok di Indonesia sangat tinggi diberbagai lapisan masyarakat, terutama pada laki-laki mulai dari anak-anak, remaja dan dewasa. Kecendrungan merokok terus meningkat dari tahun ke tahun baik pada laki-laki dan perempuan, hal ini tentu saja sangat mengkhawatirkan kita semua.
\end{abstract}


Tujuan: Penelitian ini bertujuan untuk menilai prevalensi merokok pada remaja di SMAKN 1 Kota Gianyar, Menilai pemahaman, remaja tentang bahaya merokok sesuai dengan Peringatan Kesehatan Bergambar (PKB) di satu SMAKN 1 di Kota Gianyar, Menilai pengaruh PKB, bahaya merokok terhadap perilaku merokok pada remaja di Kota Gianyar.

Metode Penelitian: ini adalah penelitian observasional dengan rancangan cross-sectional. Sampel pada penelitian ini adalah remaja laki-laki di SMKN 1 Gianyar, selama bulan Agustus 2019. Sampel dipilih secara random. Pengumpulan data melalui wawancara tersetruktur menggunakan kuisioner yang telah diuji sebelumnya, kemudian dianalisis secara Deskriptif.

Hasil : Rerata responden berusia 15,9 tahun, $100 \%$ laki-laki, berpendidikan Sekolah Menengah Atas, 97\%-99 \% responden sudah tau bahaya tentang merokok, 74\% responden mencoba-coba merokok dan rerata usia mencoba rokok pertama kali 14,2 tahun, kemudian $68 \%$ setelah adanya PKB merasa takut untuk merokok dan 30\% yang tetap ingin merokok.

Kesimpulan : Sebagian besar remaja SMAKN 1 di Kota Gianyar memiliki keinginan untuk berhenti merokok, maka dari itu penting ditindaklanjuti guna memperbaiki PKB agar dapat membantu mereka dalam hal mewujudkan keinginan untuk berhenti merokok.

Kata Kunci: Peringatan kesehatan bergambar, perilaku merokok, pengaruh peringatan.

\section{PENDAHULUAN}

Merokok merupakan kebiasaan perilaku hidup seseorang yang dapat mengganggu kesehatan untuk diri nya sendiri maupun untuk orang disekitarnya. Merokok adalah perilaku menghisap rokok yang diminati oleh kaum laki-laki dan perempuan. Padahal sebagian besar masyarakat sudah mengetahui bahaya dari merokok namun pada kenyataannya merokok sudah menjadi menjadi salah satu budaya. Jumlah perokok diseluruh dunia kini mencapai 1,2 milyar orang dan 800 juta diataranya berada di negara berkembang. Menurut Organisasi Kesehatan Dunia (WHO) memperkirakan ada lebih dari 1,1 miliar perokok diseluruh dunia, dengan lebih dari $80 \%$ dari anggota yang tinggal di negara-negara berpenghasilan rendah dan menengah.
Prevalensi merokok di Indonesia sangat tinggi diberbagai lapisan masyarakat, terutama pada laki-laki mulai dari anak-anak, remaja dan dewasa. Kecendrungan merokok terus meningkat dari tahun ke tahun baik pada laki-laki dan perempuan, hal ini tentu saja sangat mengkhawatirkan kita semua. Berdasarkan data prevalensi merokok menurut (Kementerian Kesehatan Republik Indonesia, 2018) didapatkan 7,2\%, SIRKESNAS 2016 didapatkan data sebesar 8,8\%, dan RKD 2018 didapatkan sebesar $9,1 \%$ hal ini menunjukkan prevalensi merokok pada penduduk umur 10-18 tahun memiliki kecendrungan meningkat. Berdasarkan data nasional per kabupaten/kota tahun 2017 didapatkan prevalensi merokok di jembrana $(17,60 \%)$, Gianyar $(8,90 \%)$, dan Denpasar $(4,40 \%)$. 
Kebiasaan merokok pada remaja dipengaruhi oleh beberapa faktor seperti, lingkungan, dan pajanan iklan. Lingkungan sosial kesehariannya di mulai dari sekolah (guru yang merokok) dan rumah mempunyai orang tua atau teman sebaya yang merokok hal ini sangat berpengaruh terhadap rangsangan orang untuk mencoba, merasakan apa itu rokok. Alasan lain dikarenakan ingin diterima di suatu kelompok sosial agar tidak dianggap cupu atau katrok, kemudian remaja menganggap bahwa merokok dianggap bergaya dan bisa menambah rasa percaya diri hal ini bisa dilihat dari iklan rokok yang tayang di berbagai media selalu menampilkan sosok laki-laki kuat, dan keren.

Berbagai usaha telah dilakukan pemerintah untuk mengurangi, dan menghentikan aktivitas merokok bagi masyarakat, serta mewujudkan masyarakat yang sehat, Kementerian Kesehatan Republik Indonesia melakukan perubahan pada PKB pada kemasan rokok. Melalui perubahan PKB ini diharapkan dapat meningkatkan kesadaran perokok dan bukan perokok akan bahaya rokok. Diharapkan juga masyarakat mampu memikirkan resiko atau bahaya yang di dapatkan dengan membeli atau mengkonsumsi rokok. Untuk itu penting di nilai pengaruh/efektivitas peringatan kesehatan bergambar terhadap perilaku merokok pada remaja.
Berdasarkan uraian diatas peneliti tertarik untuk melakukan penelitian tentang gambaran pengaruh kesehatan bergambar pada kemasan rokok terhadap perilaku merokok pada remaja di SMKN 1 Kota Gianyar.

\section{METODE PENELITIAN}

Penelitian ini merupakan studi observasional yang mempelajari hubungan antara faktor resiko dengan efek, pengukuran terhadap variable bebas dan variable tergantung hanya dilakukan sekali dalam waktu yang bersamaan, menggunakan desain cross-sectional analitik. Kata satu saat bukan berarti semua subyek diamati tepat pada satu saat yang sama, tetapi artinya tiap subyek hanya diobservasi satu kali dan pengukuran variable subyek dilakukan pada saat pemeriksaan tersebut (sugiyono, 2011).

\section{HASIL DAN PEMBAHASAN}

Dalam penelitian ini pengumpulan data dilakukan dengan cara membagikan kuisioner secara langsung kepada responden yang berhasil ditemui. Pengambilan data dilakukan pada bulan Maret 2019, dengan bantuan enumerator berjumlah 2 orang yang terdiri dari mahasiswa program studi ilmu Keperawatan STIKes Wira Medika Bali. Sebelum turun ke lapangan untuk mengambil data 2 orang enumerator tersebut sudah diberikan 
pengarahan bagaimana cara dan sistem dalam mengambil data pada saat di lapangan. Pengambilan data dilaksanakan selama 1 minggu, dalam hal ini peneliti memilih responden dengan menggunakan metode random sampling.

Hasil penelitian ini disajikan dalam bentuk tabel seperti berikut:

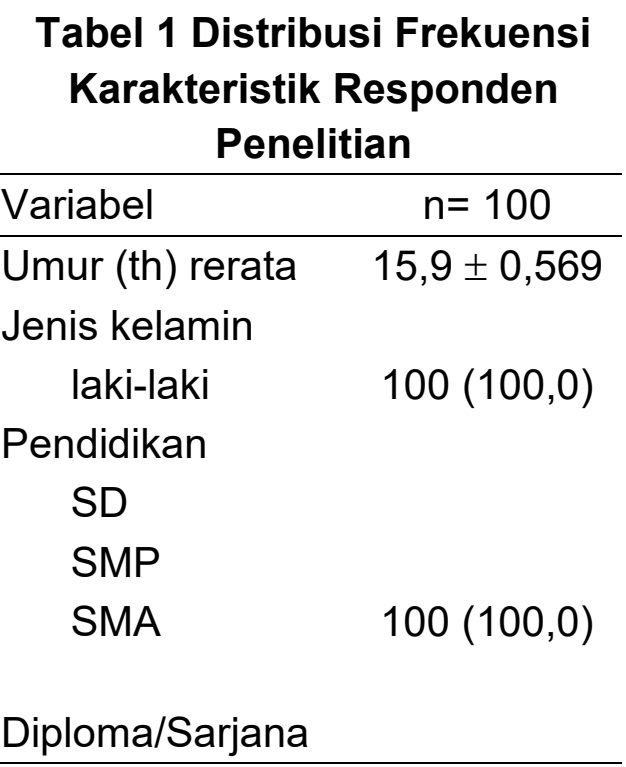

Berdasarkan Tabel 1 dapat diketahui bahwa responden adalah berjenis kelamin laki-laki sebanyak $100 \%$ responden, dengan rerata usia 15,9 th dan semua responden masih mengenyam pendididkan Sekolah Menengah Atas (SMA). Hal ini sesuai dengan data prevalensi merokok pada laki-laki lebih tinggi dibandingkan perempuan, dikarenakan merokok merupakan symbol keperkasaan lakilaki serta hal yang tabu dilakukan jika merokok dilakukan oleh seorang perempuan (Kementerian Kesehatan Republik Indonesia, 2018).

Menurut kelian, ditemukan bahwa jenis kelamin juga memberikan kontribusi dalam melatar belakangi seorang remaja laki-laki menjadi perokok. Hal ini disebabkan, remaja merasa bahwa laki-laki itu kebanyakan merokok. Dalam hal ini merokok dipandang sebagai alat untuk menunjukkan kejantanan dan jati diri seorang remaja laki-laki (Kelian, Alimudin, Syafri, Ushuluddin, \& Ambon, 2016).

Tabel 2. Pengetahuan Tentang Bahaya Rokok Pada Remaja Di SMAKN 1 Kota Gianyar

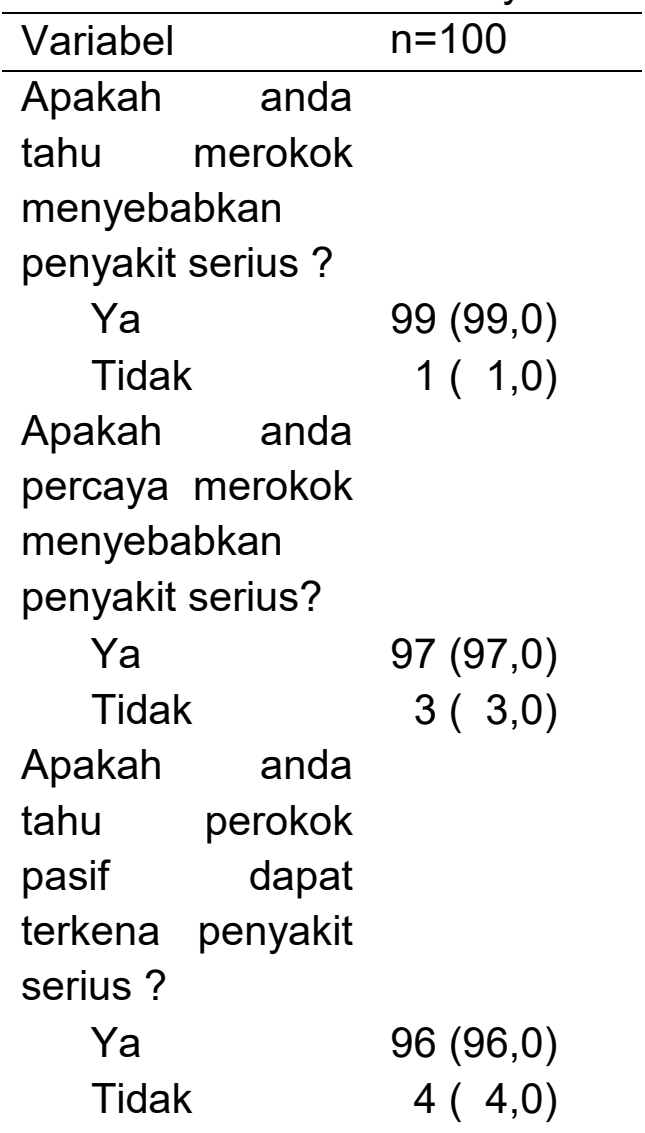


Apakah anda percaya rokok bersifat adiktif?

$99(99,0)$

Ya $1(1,0)$

Tidak

Tabel 2 menunjukkan remaja yang tahu bahwa merokok menyebabkan penyakit serius sebesar $99 \%$. Remaja yang percaya bahwa merokok menyebabkan penyakit serius sebesar 97\%. Remaja yang tahu perokok pasif dapat terkena penyakit serius sebesar $96 \%$. Remaja yang percaya rokok bersifat adikitif sebesar 99\%. Secara keseluruhan hasil tersebut menunjukkan bahwa remaja laki-laki di SMA di Kota Gianyar sudah baik. Dibandingkan dengan penelitian sebelumnya didapatkan bahwa sebanyak 41 dari 79 responden (52\%) (Rahayu, 2017), maka hasil di kabupaten gianyar sudah lebih tinggi. Hal ini berarti sudah terjadi peningkatan pengetahuan dari tahun 2017 sampai tahun 2019. Salah satu faktor peningkatan pengetahuan ini adalah peringatan kesehatan bergambar. Tabel 3 Penilian Perilaku Merokok Pada Remaja di SMAKN 1 Gianyar

Tabel 3. Penilaian Perilaku Merokok Pada Remaja di SMAKN 1 Gianyar

\begin{tabular}{lll}
\hline Variabel & $\mathrm{n}=100$ & di Kota Gianyar \\
\hline & Variabel & \\
& &
\end{tabular}

Apakah anda pernah

mencoba-coba

merokok?

$\mathrm{Ya}$

$74(74,0)$

Tidak $26(26,0)$

Berapa usia anda, ketika anda pertama kali merokok, rerata \pm SD $14,2 \pm 1,253$

Apakah anda sekarang jadi terbiasa merokok?

Ya $22(22,0)$

Tidak $78(78,0)$

Sumber: data pribadi

Berdasarkan table 3 dapat diketahui bahwa proporsi remaja yang terbiasa merokok sebesar 22\%. Proporsi ini menunjukkan jumlah remaja merokok masih tinggi sehingga dapat dikatakan sebagai prevalensi. Prevalensi remaja merokok sebesar $22 \%$, hal ini sesuai dengan hasil global youth Survei dimana didapatkan sebanyak $21 \%$ remaja yang merokok (World Health Organization Regional Office for South-East Asia, 2014). Hasil penelitian ini menunjukkan prevalensi pada remaja masih tinggi, padahal target nasional remaja perokok harus diturunkan menjadi $10 \%$.

Tabel 4. Pengaruh PHW Terhadap Perilaku Merokok Pada Remaja SMA 


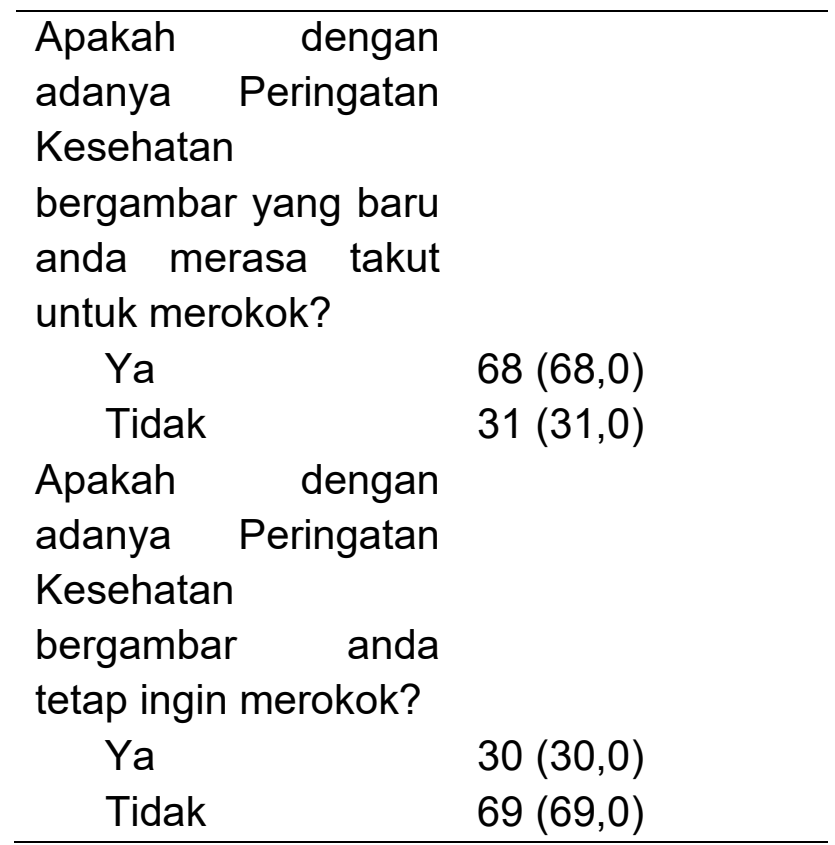

Sumber: data pribadi

Berdasarkan tabel 4 dapat dilihat bahwa dengan adanya peringatan kesehatan bergambar yang baru remaja yang merasa takut untuk merokok didapatkan sebanyak 68\% responden, kemudian remaja yang ingin tetap merokok didapatkan sebanyak $30 \%$. Hasil ini sejalan dengan penelitian sebelumnya yang berjudul Opini, Dukungan Masyarakat dan Efektivitas Peringatan Kesehatan Bergambar Terhadap Upaya Berhenti Merokok di Provinsi Bali yang mengatakan bahwa hamper setengah (49\%) dari perokok aktif berencana berhenti merokok dan $45,4 \%$ telah mengurangi konsusmsi rokok dari rata-rata 14,5 batang perhari menjadi 10,4 batang perhari (Artawan Eka Putra et al., 2015). Sebagian besar remaja SMA di Kota Gianyar memiliki keinginan untuk berhenti merokok, untuk itu penting ditindaklanjuti untuk memperbaiki peringatan kesehatan bergambar agar dapat membantu mereka dalam hal mewujudkan keinginan untuk berhenti merokok.

\section{SIMPULAN}

Berdasarkan hasil penelitian yang dilakukan terhadap remaja laki-laki di SMAKN 1 Kota Gianyar didapatkan kesimpulan sebagai berikut:

1. Prevalensi merokok pada remaja SMA di Kota Gianyar didapatkan sebesar $22 \%$.

2. Pemahaman remaja tentang bahaya merokok sesuai dengan kesehatan bergambar didapatkan hasil yang baik yaitu sebesar $97 \%$ $99 \%$.

3. Pengaruh peringatan kesehatan bergambar, bahaya merokok terhadap perilaku merokok pada remaja di Kota Gianyar didapatkan sebesar $69 \%$ yang ingin berhenti merokok.

Berdasarkan hasil penelitian yang dilakukan terhadap remaja lakilaki di SMAKN 1 di Kota Gianyar didapatkan saran sebagai berikut:

1. Bagi orang tua, sebaiknya tidak merokok didepan anak-anaknya dan didalam rumah. Hal ini bisa membuat anak-anak mengikuti kebiasaan tersebut.

2. Bagi Dinas Kesehatan bisa meningkatkan lagi penyuluhan untuk para remaja tentang bahaya merokok. Menggingat pengetahuan remaja yang sudah baik untuk pengetahuannya, bisa 
ditambahkan dengan program posyandu untuk remaja, sebagai wadah konseling untuk anak-anak yang merokok.

\section{UCAPAN TERIMA KASIH}

Terimakasih saya ucapkan kepada STIKes Wira Medika Bali yang sudah memberikan bantuan dana kepada saya untuk melakukan penelitian ini. Terimakasih juga saya ucapkan kepada pihak sekolah yang sudah memberi ijin kepada saya untuk dapat melakukan penelitian ini, serta terima kasih saya ucapkan untuk 2 orang enumerator serta berbagai pihak yang sudah membantu saya menyelesaikan penelitian ini.

\section{DAFTAR PUSTAKA}

Artawan Eka Putra, I., Astuti, P., Duana, I., Suarjana, I., Mulyawan, K., \& Bam, T. (2015). Opini , Dukungan Masyarakat dan Efektivitas Peringatan Kesehatan Bergambar Terhadap Upaya Berhenti Merokok Di Provinsi Bali. 2nd Indonesian Conference on Tobacco or Health, 4, 77-82. Jakarata.

Kelian, M. T., Alimudin, L., Syafri, O., Ushuluddin, M. F., \& Ambon, D. I. (2016). Persepsi Perokok Aktif Dalam Menanggapi Label Peringatan Bahaya Merokok. 8, 54-65. Retrieved from https://www.google.com/search? $\mathrm{q}=$ Kelian $\% 2 \mathrm{C}+\mathrm{T} .+\mathrm{M} . \% 2 \mathrm{C}+$ Alimu din $\% 2 \mathrm{C}+\mathrm{L} . \% 2 \mathrm{C}+\% 26+$ Syafri $\% 2$ C+O.+(2016).+Persepsi+Perokok +Aktif+Dalam+Menanggapi+Labe I+Peringatan+Bahaya+Merokok. \&oq $=$ Kelian $\% 2 \mathrm{C}+\mathrm{T} .+\mathrm{M} . \% 2 \mathrm{C}+\mathrm{Ali}$ mudin $\% 2 \mathrm{C}+\mathrm{L} . \% 2 \mathrm{C}+\% 26+$ Syafri $\% 2 \mathrm{C}+$ O.+(2016).+Persepsi+Pero kok+Aktif+

Kementerian Kesehatan Republik Indonesia. (2018). HASIL UTAMA RISKESDAS 2018. Retrieved from

http://www.depkes.go.id/resource s/download/info-terkini/hasilriskesdas-2018.pdf

Noar, S. M., Hall, M. G., Francis, D. B., Ribis, K. M., Pepper, J. K., \& Brewer, N. T. (2016). Pictorial cigarette pack warnings: A metaanalysis of experimental studies. Tobacco Control, 25(3), 341-354. https://doi.org/10.1136/tobaccoco ntrol-2014-051978

Rahayu, P. (2017). Hubungan Antara Pengetahuan Bahaya Merokok Dengan Perilaku Merokok Pada Mahasiswa DI Universitas Muhammadyah Surakarta. Retrieved from http://eprints.ums.ac.id/55046/1/ NASKAH PUBLIKASI.pdf

sugiyono. (2011). Metode Penelitian Pendidikan Kuantitatif Kualitatif. Bandung: Alfabeta. 
Sychareun, V., Hansana, V., Phengsavanh, A., Chaleunvong, K., \& Tomson, T. (2015). Perceptions and acceptability of pictorial health warning labels vs text only - A cross-sectional study in Lao PDR. BMC Public Health, 15(1), 1-10. https://doi.org/10.1186/s12889015-2415-9

World Health Organization Regional Office for South-East Asia. (2014). Global Youth Tobacco Survey (GYTS): Indonesia report 2014. In Indonesia Report. Retrieved from http://www.searo.who.int/tobacco /documents/ino_gyts_report_201 4.pdf 